\title{
Dual Use and Biosecurity: The Case of the Avian Flu H5N1*
}

\author{
Pieter J. D. Drenth ${ }^{1,2}$ \\ ${ }^{1}$ Department of Psychology, VU University Amsterdam, Amsterdam, The Netherlands \\ ${ }^{2}$ Royal Netherlands Academy of Arts and Sciences, Amsterdam, The Netherlands \\ Email: pjdd@xs4all.nl
}

Received June 25, 2012; revised July 24, 2012; accepted August 1, 2012

\begin{abstract}
The classical dual use problem — the potential for harmful as well as beneficial application of scientific findings—has become more immediate in biotechnology than in most other fields of science. Terrorist misuse of the information on the development of pathogenic organisms can lead to catastrophic outcomes. Therefore, particular in biosciences researchers are faced with the dilemma to find a proper balance between the right to know and the dangers of knowing. In this paper this dilemma is illustrated by the research on the influenza A virus subtype H5N1, commonly known as "bird flu". The pros and cons of the full publication on the development of a dangerous airborne type are discussed.
\end{abstract}

Keywords: Dual Use; Biosecurity; Biosafety; Bird Flu

\section{Introduction}

The dual use problem - the potential for harmful as well as beneficial applications of ideas, findings, discoveries, tools and instruments - has been with us since the early days of evolution. A stick could be used to rake bananas beyond reach or to beat a congener, iron could be melted to forge ploughshares or swords.

This applies to science as well. Scientific knowledge can also be used for the better or for the worse. Nuclear fission can be utilised for the production of clean energy or for the development of an atomic bomb. The analysis of pain can be applied for the development of effective sedatives or of torturing interrogation means. Audiometric research can result in improved communication for people hard of hearing or in criminal telephone tapping.

The scientific world has always been reluctant to accept constraints on research and to admit "no go" decisions for certain subjects or fields of investigation. In the first place because in principle nearly all results of scientific research are open for wilful abuse. Prohibition of scientific research for the fact that its results could be abused or irresponsibly applied would, therefore, mean the end of almost all research. Secondly, because undesirable or dangerous consequences of research are not always easy to chart, especially in fundamental or innovative research with its creativity and serendipity. In the third place because the arguments "undesirable" and "dangerous" have too often been led to repression by

\footnotetext{
*This paper is based on a presentation at the General Meeting of the International Human Rights Network of Academies and Scholarly Societies in Taipei, Taiwan, on May 23-25, 2012.
}

dictators, governments, political authorities, economic sponsors or popular action movements (environment, feminism, anti-discrimination). One only has to remember Galileo, Spinoza, More or in modern times Lysenko and Sacharov to realize how innovative scientists and scholars can be victimised if their results do not find favour with the rulers in power.

It should be realised that, if there is a question of constraints on science, it is the scientific world itself that should impose such restrictions. Legislation and bureaucratic regulations would be largely ineffective. Of course, there are cases for which "no go" decisions would be considered incontestable by all scientists and scholars. For instance, cases in which unacceptable harm or damage is inflicted upon the object of research (human beings, animals, nature, cultural products), or cases in which the nature or consequences of the research would be in conflict with basic human values (human rights, human dignity, equality, and non-discrimination (for a more extensive discussion see Drenth, [1]). But, as said, there is a strong disinclination to interdict research because of its potential misuse, and to go beyond the fostering of scientists' responsibility through training and awareness programmes, and through the development of codes and professional standards.

\section{Biosecurity}

Recently, however, this state of affairs underwent a change. Incited by two deterrent incidents, the attack with nerve gas in a Japanese metro in the mid 90's, and the distribution of anthrax letters in the USA shortly after the 9 - 11 
raid, one realised that abuse of biological research could assume enormous proportions.

What types of potential misuse can be distinguished? The US National Research Council [2,3] mentions seven classes of experiments that raise concerns about their potential for misuse, including those that would:

- Demonstrate how to render a human or animal vaccine ineffective;

- Provide pathogens with resistance to therapeutically useful antibiotics or antiviral agents;

- Enhance the virulence of a pathogen or render a nonpathogen virulent;

- Increase transmissibility of a pathogen;

- Alter the host range of a pathogen;

- Enable the evasion of diagnosis or detection;

- Enable the weaponisation of a biological agent or toxin.

Already in 1972 a "Biological and Toxin Weapons Convention" had been signed by a great number of states (by the year 2000 some 144 states plus 18 signatory states). Article 1 of the BWC reads: "Each state party to this Convention undertakes never in any circumstances to develop, produce, stockpile or otherwise acquire or retain microbial or other biological agents, or toxins whatever their origin or method of production, of types and in quantities that have no justification for prophylactic, protective or other peaceful purposes". But terrorists make light of such conventions and the threat of massive harm may not be at all unrealistic. And it may be a mistake to think of terrorists as just loners working in their garage with bombs and kalashnikovs.

On 7 November 2007 the international panel IAP (a global network of science academies [4]) issued a statement on biosecurity, representing fundamental biosecurity issues that should be taken into account when formulating codes of conduct. These include:

- Awareness: Scientists should always bear in mind the potential (harmful) consequences of their research, and refuse to undertake research that has only harmful consequences for humankind;

- Safety and security: Good, safe and secure laboratory procedures;

- Education and information on national and international laws and regulations, as well as policies and principles aimed at preventing misuse of biological research;

- Accountability: Scientists aware of violations of the BWC should raise concerns with appropriate people, authorities and agencies;

- Oversight: Scientists with responsibility for oversight of research or evaluation of projects should adhere to these principles.

This statement was supported by 67 national Academies of Sciences plus TWAS (the Academy of Sciences for the Developing World). As can be seen, this statement strongly emphasises the responsibility of the scientists themselves.

The Royal Netherlands' Academy of Arts and Sciences (KNAW), that has been an active contributor to the IAP Statement, produced a "Code of Conduct for Biosecurity" also in 2007 [5]. In addition to issues mentioned above this code also includes rules of conduct on:

- Research and Publication policy: Be aware of and screen for dual-use aspects during the execution of research, and reduce the risk of potential misuse of published results;

- Internal and external communication: Maintain appropriate security for e-mails, post, telephone calls and data storage concerning information about potential dual-use research or materials;

- Accessibility: Screening with attention to biosecurity aspects of staff and visitors;

- Shipment and transport: Screening on biosecurity aspects of transporters and recipients of potential dualuse materials.

It may be good to point out the difference between biosafety and biosecurity. The former concept deals with the danger that a dangerous virus or pathogen escapes the laboratory or repository or that someone at the laboratory may have an accident, and the precautionary measures that researchers have to take to avoid this risk. The latter concept refers to the risk of wilful abuse of research in the hands of a nefarious terrorist, and is more specifically the subject of this paper.

A pressing question, then, is how to regulate the biological research in view of this threat of malignant use. Many scientists, including the majority of respondents in a survey of AAAS and the US National Research Council [6], hold the view that scientists themselves should shoulder this responsibility. They favour self-governance, through creating awareness and responsibility, through enlightened leadership (Franz [7]), by cultivating a moral agency of individual scientists or groups of scientists (Davis [8]), by enunciating norms and codes (Epstein [9]), through educating junior scientists about dual use (Sta.Ana, Frankel and Berger [10]), and through oversight mechanisms for research proposals and publiccations in which peer reviewers try to answer the question whether the scientific value of the (to be) gained knowledge outweighs the risks of malignant abuse. On the other hand it is also defended that the threat of misuse does not stem primarily from within the scientific community, but from terrorists who have gained access to the scientific knowledge and do not share the scientists' moral imperative. It is then concluded that a national government should assume the responsibility and should take action through legislation and control. The US has taken a step in the latter direction by founding a National 
Science Advisory Board for Biosecurity (NSABB), an independent committee that advises the US Department of Health and Human Services and other federal agencies on (the publication of) biological research that may endanger biosecurity. Although many of the recommendations of the NSABB tend to stress the importance of self-governance and own responsibility of scientists, it opens the opportunity for a governmental regulation or action.

It will be clear that, next to the question whether such a governmental control could ever be feasible and effective (and Epstein [9]) shows with good arguments that it is not), we are also confronted with the more fundamental questions of freedom of research and inquiry, freedom of speech and publication, and the balance between the right to know and the dangers of knowing. Many scientists feel that even well intended efforts to restrict the freedom to share and to publish their research findings may have serious consequences, both in terms of lost knowledge and wrong application of existing knowledge. A good deal of this discussion can be illustrated on the basis of a recent case at the Medical Faculty of the Erasmus university in Rotterdam, where Ron Fouchier and his colleagues modified the avian flu H5N1 to be transmissible via aerosols or respiratory droplets, and submitted a publication on this experiment to Science. We will discuss some details of this case in the remainder of this paper ${ }^{1}$.

\section{The H5N1 Avian Flu Case}

\subsection{The Facts}

For quite some time a group of virologists at the Department of Virology, Erasmus Medical Center in Rotterdam, led by Ron Fouchier, has researched the Influenza A virus subtype H5N1, more commonly known as "bird flu". Since its first detection in 1997 this highly pathogenic virus has killed hundreds of millions of birds, but so far the virus caused only 577 (laboratory confirmed) cases of human infections, and only in people who had been in close contact with infected poultry. Sustained human-to-human transmission has not been reported (Fouchier, Herfst \& Osterhaus [11]). It is, however, a fairly lethal virus in people, having killed, according to some estimates, around $60 \%$ of those 577 infected individuals. And if this virus were to mutate to an airborne type, which could be transmitted through coughs and sneezes or via aerosols, a devastating pandemic must be expected.

\footnotetext{
${ }^{1} \mathrm{~A}$ comparable study resulting in a similar contagious mutant of the avian flu has been carried out by Yoshihiro Kawaoka at the University of Wisconsin, Madison. His paper was sent for publication to Nature, and was subjected to a similar treatment as Fouchier's paper. As said, we will focus on the latter.
}

Yet this is what Ron Fouchier and his assistant Sander Herfst discovered. Through five mutations they modified the virus into an airborne, and thus extremely contagious, version. The research was done in ferrets, which catch flu somewhat similar to the way humans do, and which are considered the best models for such a test. The virology group at the Erasmus University had asked and received permission as well as funding to do this cutting-edge research. They have followed carefully the rules of conduct prescribed in the IAP Statement and the KNAW Code of Conduct for Biosecurity. Fouchier described his work and data at the influenza conference organised by the European Scientific Working Group on Influenza (ESWI) in Malta in September 2011, and submitted a manuscript with the full information for publication in Science. The Science editors first conducted their own biosecurity review (in agreement with the IAP statement and the Dutch Code of Conduct for Biosecurity), and sent it also to the NSABB for advice. The NSABB recommended to the US government that the conclusions of the manuscript could be published, but without experimental details and mutation data that would enable replication of the experiments. NSABB further recognised that detailed information about the results should be shared under confidentiality with parties that "need to know” (Fouchier, Herfst \& Osterhaus, [11, p.2]).

In the meantime it has become a notorious case. It was subject of an often heated debate in the scientific press, but also in the public media, especially after the publication of an article "Debate persists on deadly flu made airborne” in the Science section of the New York Times on December 26, 2011, and the large number of comments that it provoked. Critics charge Fouchier and his group with the accusation that he should not have created the virus in the first place, and insist that this research should not be published.

The authors do not agree with the NSABB recommendations, but respect nevertheless their advice. They were willing to submit an article version that does not include the methodological and other details that could enable replication of the experiments by criminals, and to try to find a solution for disseminating key information to those who need to know. In a statement in Nature and Science by the end of January 2012 all 39 influenza researchers who work at virology laboratories where such experiments could be carried out endorsed a 2 months moratorium on studies that make the avian influenza strain H5N1 more transmissible between mammals, in order to make time for an international debate on its biosecurity consequences.

\subsection{The Debate}

The arguments contra are clear: The risk of terrorist misuse of the information is considered bigger than the 
negative effects of strangling such research through restrictive measures and regulations. "Some cases are worth an exception to the principle of openness" said Thomas Inglesby, the director of the Centre for Biosecurity at the University of Pittsburgh in an interview for Mailonline (18-11-2011). Epstein (2012) reasoned that the argument that this kind of advanced basic research cannot be understood or applied by terrorists may be an illusion. "Today's cutting-edge research becomes tomorrow craft skill, which becomes the day after's commodity", as he stated. The conclusion is that the risks outweigh the benefits, and that, therefore, this research should not be done, and certainly not be published.

At the same time a number of good arguments pro have been brought to the fore.

In the first place, there is the importance of knowing and sharing knowledge with other scientists. Openness and sharing knowledge is the cornerstone of scientific development. And this scientific development cannot be stopped. Fouchier, Herfst and Osterhaus [11] point out that they only used information and methods that are available freely from the scientific literature, and that virologists could perform similar experiments even if their method is not published.

The NSABB recommendation to publish the results, but without the experimental details and the mutation data that would allow replication of the experiments, does not seem an effective and feasible solution. Science can only develop through critical analysis and replication by colleague scientists, and they need full details for that. NSABB realised this also, and recommended, as said, that detailed information should be shared confidentially with to be approved experts that need to know. However, aside from the near impossibility to keep such a publication secret very difficult questions arise immediately: Who decides about the approval? Using which criteria? Which mechanism will be used to share the information? In addition, within the legal rules of the World Health Organisation (WHO) it is very difficult to refuse information on a dangerous and contagious virus to any state that requests such information.

Moreover, in this case there is the important implication for public health. What can be done in a lab can also spontaneously happen in nature, and it is good to know which mutations to watch for in case of an outbreak, and to prepare for a timely development of vaccinations and medication. As Fouchier, Herfst and Osterhaus [11] state "nature itself should be considered the prime bioterrorist". Without knowledge of the possibility of this vicious variant confidence in the traditional H5N1 strategy (only birds and no airborne contagion) would be seriously fallacious. In addition, lots of further questions need to be researched: How does this virus spread between people? How important is the aerogene spread? How stable is the mutation? Can we generalise from ferret to human? The view of the virologist Palese [12] is almost the opposite of the NSABB advice: "The more danger a pathogen poses, the more important it is to study it and to share the results with the scientific community. Slowing down the scientific enterprise will not protect the public, it only makes us more vulnerable.”

Finally, pre-screening and censorship has a rather harmful side-effect: Who would enter a research field and carry out complex and time consuming research without a guarantee that the significant results can be published? Essentially, such restrictive measures would terminate frontier research in this field of great importance.

\subsection{Latest Developments}

On 16-17 February 2012 the WHO organised an expert meeting with a strong representation of the influenza field, in which the importance of this kind of research was unanimously underscored. A further consensus was reached on the view that a shortened re-edited version of the manuscript has no value, that sharing the details of the study with a restricted, selected number of colleagues is not practicable, and that the benefits of the research for science and public health are greater than the possible risks of publication.

Further, neither the US government nor the WHO has found practicable ways to share details of this research confidentially only with selected colleagues. After the Geneva WHO conference and the ardent discussions in the professional and public press the US government requested a second opinion of the NSABB. Fouchier and Kawaoka were asked to defend their research and to formulate their objections against the first advice. Given their arguments and the conclusions of the Geneva conference NASBB changed its opinion and decided now to advise positively on the publication of the full manuscripts.

The US government accepted this NASBB advice.

The Dutch government did not agree, however, and insisted on its right to exercise export control over this potentially dangerous research, which is considered applied research. (The government has no right to wield power over basic research). It forced Fouchier and his group to ask permission for export, which they did under protest. After careful weighing of the (scientific and public health) interests and the risks the government as yet granted the export and the research was published.

\section{Conclusions}

The contentious issue discussed in this paper is a good illustration of the dilemmas that dual research raises. Taking extreme positions in such a dilemma should be 
denounced. Both the extreme view of zero tolerance with respect to the risks of research on dangerous viruses as well as the extreme view that entirely dismisses these risks, stressing the scientific progression and public health benefits, have to be avoided. Personally I am inclined, given the convincing arguments pro, as discussed above, to pronounce against the prohibition of this type of research and its full publication, provided the researchers take all necessary Biosafety measures, and comply fully with the Code of Conduct for Biosecurity. However, which stand one takes on the continuum between the two extreme positions remains a personal choice, but should - contrary to the often indignant reactions in the public media-always be based on full and reliable information, and result from a careful and responsible weighing of the risks and benefits.

The H5N1 case is an instructive illustration of the dual use dilemmas in present day's developments in biotechnology. Given the uncertainties and lack of clarity with respect to the distribution of responsibilities between the scientific world and governments in many parts of the world further and better regulations are needed. In my opinion Academies of Sciences, and International Associations of Academies of Sciences (such as ALLEA and IAP) are the right institutes to take up this gauntlet.

\section{REFERENCES}

[1] P. J. D. Drenth, "Science: Where Do We Draw the Line," European Review, Vol. 7, No. 2, 1999, pp. 239-246. doi:10.1017/S1062798700004014

[2] National Research Council, "Biotechnology Research in an Age of Terrorism,” NA Press, Washington DC, 2004.
[3] National Research Council, "Understanding Biosecurity; Protecting against the Misuse of Science in Today's World,” NA Press, Washington DC, 2010.

[4] Inter Academy Panel, "IAP Statement on Biosecurity," Third World Academy of Sciences, Trieste, 2005.

[5] Koninklijke Nederlandse Akademie van Wesenschappen, “A Code of Conduct for Biosecurity,” Amsterdam, 2007. knaw@bureau.knaw.nl

[6] National Research Council, "Understanding Biosecurity; Protecting against the Misuse of Science in Today's World," Nuclear Regulatory Commission, Washington, 2009.

[7] D. R. Franz, "The Role of Leadership and Culture within the Laboratory,” In: T. Mayer and N. Steneck, Eds., Promoting Research Integrity in a Global Environment, World Science Publishing Co., Singapore, 2010, pp. 365-368.

[8] F. D. Davis, "Dual-Use Research, Codes of Conduct, and the National Science Advisory Board for Biosecurity,” In: T. Mayer and N. Steneck, Eds., Promoting Research Integrity in a Global Environment, World Science Publishing Co., Singapore, 2012, pp. 369-374.

[9] G. L. Epstein, "Governance Options for Dual Use Research,” In: T. Mayer and N. Steneck, Eds., Promoting Research Integrity in a Global Environment, World Science Publishing Co., Singapore, 2012, pp. 391-364.

[10] J. L. S. Ana, M. S. Frankel and K. M. Berger, "Educating Scientists about Dual Use,” Science, Vol. 326, No. 5957, 2009, p. 1193. doi:10.1126/science.1176127

[11] R. A. M. Fouchier, S. Herfst, and Osterhaus, "Restricted Data on Influenza H5N1 Virus Transmission," Science Express, Vol. 335, No. 6069, 2012, pp. 662-663. doi:10.1126/science.1218376

[12] P. Palese, "Don’t Censor Life-Saving Science," Nature, Vol. 481, No. 115, 2012. doi:10.1038/481115a 